\title{
New ecological options for the management of horticultural crop pests in Sudano-Sahelian agroecosystems of West Africa
}

A. Ratnadass ${ }^{1,2}$, Z. Claude $^{2,3}$, A. Nikiema ${ }^{2}$

D. Pasternak ${ }^{2}$, P. Ryckewaert ${ }^{1}$

K. Thunes ${ }^{4}$, L. Woltering ${ }^{2}$

\& O. Zakari-Moussa ${ }^{3}$

1. Cirad, UR HortSys, Montpellier, France 2. Icrisat, Niamey, Niger

3. Abdou Moumouni University, Niamey, Niger

4. Norwegian Institute for Forest \& Landscape, Norway

Further to earlier studies on the agroecological management of annual crop pests in Niger[1], presented studies highlight the potential for mobilizing aerial and soil-bound ecological processes for managing the main pests of grafted jujube and Moringa trees, the major perennial species in the rainwater harvesting-based Bio-Reclamation of Degraded Lands (BDL) system[2], Moringa being also popular in the drip irrigation-based African Market Gardens (AMG)[3]. Both BDL and AMG are promoted by ICRISAT as water-saving, food-securitizing and income-generating cropping systems for Sudano-Sahelian Africa.

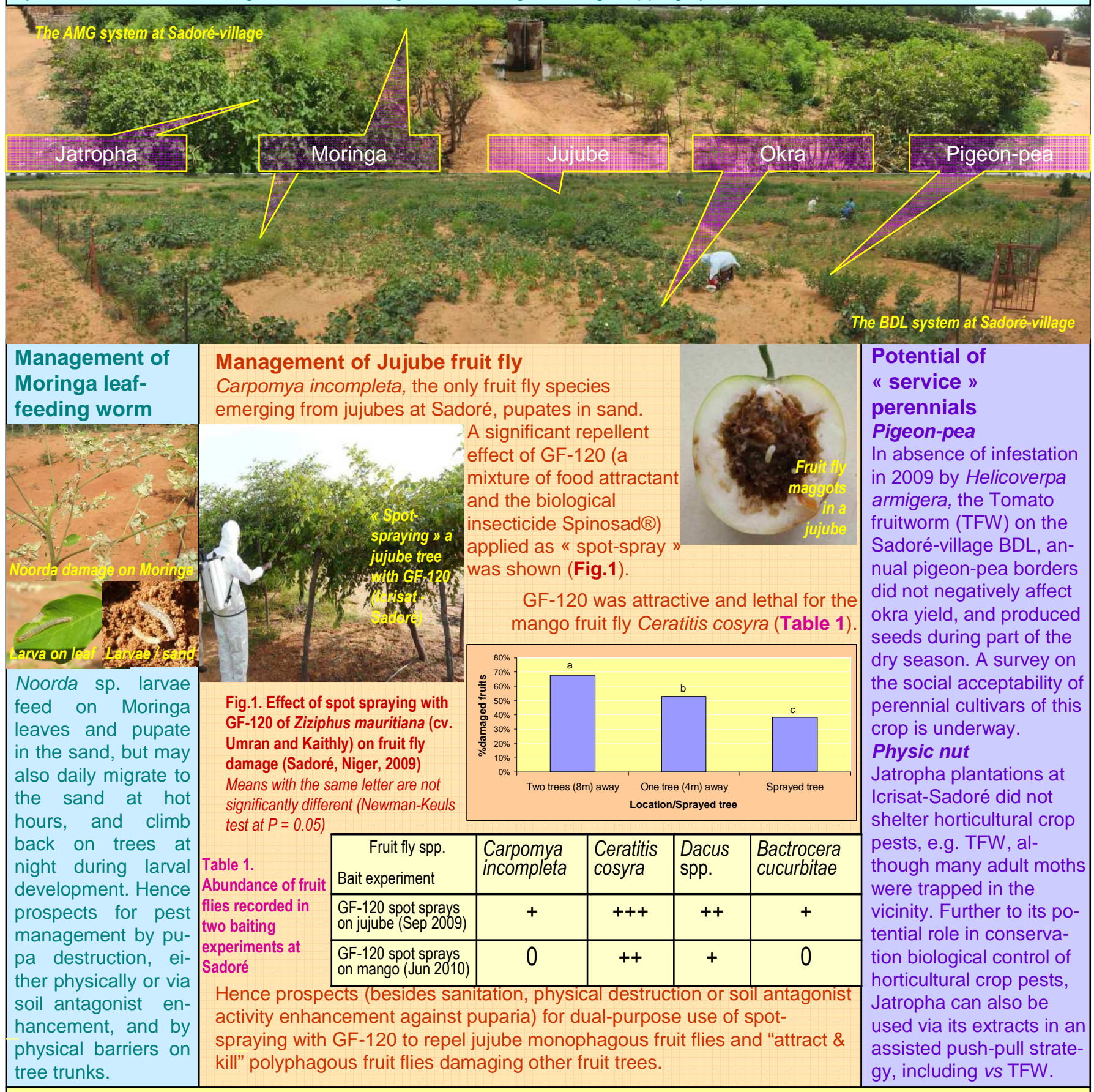

Future prospects: Other non-chemical options for Moringa leaf-worm and jujube fruit fly control should also be tested, e.g. neem extracts could be used as repellents on both pests, in combination ("assisted push-pull") with resp. spot-spraying in the case of fruit flies, and trap-cropping in that of TFW. Neem tree, being traditionally grown as a wind break around fruit tree orchards, can be considered, like Jatropha, as a service perennial for Sudano-Sahelian horticultural systems.

References:
[1] Ratnadass, A., et al. 2009a. Proc. 18th AAIS Conference, 16-20 Nov 2009, Ouagadougou;

[2] Pasternak D., et al. 2009. Chronica Hort. 49:24-26;

[3] Pasternak, D., et al. 2006. Chronica Hort. 46:24-28;

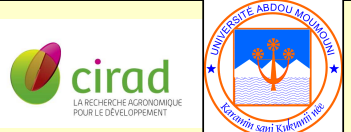

